\title{
A IMIGRAÇÃO PARAGUAIA CONTEMPORÂNEA: ELEMENTOS PARA A SUA COMPREENSÃO
}

\author{
Alena Profit
}

\section{Introdução}

As transposições entre diferentes escalas de espaço, tempo e simultaneidades ${ }^{1}$ trazem à tona os entrelaçamentos espaciais e temporais da mudança social. Nesse sentido, o exercício de reflexão ${ }^{2}$ sobre os fluxos migratórios paraguaios em direção ao Brasil se constitui de modo complexo, tendo em vista que envolve elementos de ordens distintas e realidades sociais mutáveis.

Vários autores destacam a historicidade desses fluxos ${ }^{3}$. Após a colonização e a posterior independência do Paraguai, percebeu-se uma intensificação do processo emigratório paraguaio com a formação de diásporas em outros países, ao longo do século XIX, até os processos migratórios contemporâneos. Para ilustrar, o quadro a seguir resume aspectos relevantes que contribuem para a compreensão dos movimentos emigratórios paraguaios a partir do século XIX.

Quadro 1.1: Migrações por países, ciclos e causas

\begin{tabular}{|c|c|c|c|c|c|c|}
\hline $\begin{array}{c}\text { Destino } \\
\text { preferencial }\end{array}$ & Argentina & $\begin{array}{c}\text { Mato } \\
\text { Grosso }\end{array}$ & Argentina & $\begin{array}{c}\text { Argentina } \\
\text { e Uruguai }\end{array}$ & $\begin{array}{c}\text { Argentina, } \\
\text { EUA, EU, } \\
\text { Brasil }\end{array}$ & $\begin{array}{c}\text { Argentina, } \\
\text { EUA, EU, } \\
\text { Brasil }\end{array}$ \\
\hline Anos & $1811 / 1850$ & $1870 / 1880$ & $1900 / 1930$ & 1947 & $1960 / 1970$ & $1989 / 2009$ \\
\hline Causas & Ditaduras & Pós-guerra & $\begin{array}{c}\text { Econômicas } \\
\text { e políticas }\end{array}$ & Guerra civil & $\begin{array}{c}\text { Econômicas } \\
\text { e ditadura }\end{array}$ & $\begin{array}{c}\text { Recessão e } \\
\text { desemprego }\end{array}$ \\
\hline
\end{tabular}

Fonte: PNUD (2009)

Mestranda em Ciências Sociais pelo Centro de Pesquisas e Pós-Graduação sobre as Américas da UnB (CEPPAC). Brasília/Brasil.

1 LEVITT, Peggy; GLICK-SCHILLER, Nina. Conceptualizar a simultaneidade.

2 O contexto desta pesquisa em andamento se debruça sobre dinâmicas familiares no contexto da imigração paraguaia em direção ao Brasil.

3 CESPEDES, Roberto. Familias en Paraguay. Análisis sociohistórico de estructuras familiares y pobreza; ODDONE, Hugo. Algunas consideraciones sobre los fundamentos ideológicos de la política migratoria paraguaya; PALAU, Tomás. El Marco expulsivo de la migración paraguaya. Migración interna y migración externa. 
Desde o século XX, a emigração de paraguaios para outros países tem sido crescente $^{4}$. A dimensão econômica é um viés que assegura ainda mais a relevância de se debruçar sobre a migração paraguaia. De acordo com a Comissão Econômica para a América Latina e o Caribe $^{5}$, as remessas enviadas por paraguaios vivendo no exterior representavam 3,7\% do PIB paraguaio. A importância da dimensão política da emigração se evidencia também nas formas de organização dos paraguaios fora do país. Destaca-se como marco político a realização de um referendo no ano de 2011 para a modificação do artigo 120 da Constituição do Paraguai, a respeito da concessão de voto aos paraguaios residentes fora dopaís. Como destaca Halpern, "[e]n España, Francia, Estados Unidos, Brasil, Bélgica, Italia, Argentina, Austria y, por cierto, en Paraguay, las organizaciones consideraron un "triunfo político" haber logrado una victoria tan abultad"6.

No âmbito dos fluxos migratórios paraguaios, também se revela a forte inter-relação entre a migração interna e internacional ${ }^{7}$. De acordo com a Encuesta Permanente de Hogares (EPH) de 2009, mais de 12,9\% da população pertencia à categoria de migrantes internos, dos quais 5,2\% realizaram um deslocamento urbano-urbano; 2,7\% urbano-rural; 2,3\% rural-urbano; e 2,8\% rural-rural. Um olhar mais profundo sobre os levantamentos estatísticos tambémtraz um perfil a respeito do perfil dos emigrantes internacionais: de acordo com a Encuesta Permanente de Hogares (EPH) de 2008, a porcentagem de emigrantes entre 15 e 29 anos representa três quartos do total da população migrante paraguaia.

No mesmo levantamento, consta que são majoritariamente, cerca de $66 \%$, as filhas das ou dos chefes de família dos domicílios que migram, seguidas posteriormente pelo cônjuge ou outro parente. Como demonstram esses dados, os desdobramentos da migração vão além e se revelam na esfera familiar. A partir de 2001, mais de $8 \%$ da população paraguaia teve algum membro residente que morou no exterior nos últimos cinco anos ${ }^{8}$.

Segundo os dados obtidos pela Encuesta Permanente de Hogares de 2009, publicada pela Dirección General de Estadística, Encuestas y $\operatorname{Censos}^{9}$ paraguaia em 2010, a migração se destaca como majoritariamente feminina e oriunda de áreas rurais, sendo que a migração paraguaia para a Argentina é composta por $55,7 \%$ de mulheres e para a Espanha por 61\%. Conforme demonstra o quadro a

4 CESPEDES, op. cit.

5 CEPAL. América Latina y el Caribe: migración internacional, derechos humanos y desarrollo.

6 HALRPERN, Gerardo. Historia de un hecho histórico: Referéndum constitucional y migración paraguaya, p. 1.

PALAU, op. cit.

8 CEPAL, op. cit.

9 DIRECCIÓN GENERAL DE ESTADÍSTICA, ENCUESTAS Y CENSOS (DGEEC). Principales resultados de pobreza y distribución del ingreso. EPH, 2009. 
seguir, a Argentina e a Espanha constituem os principais destinos dos migrantes paraguaios, seguidos por Brasil e Estados Unidos.

\section{Quadro 1.2. População paraguaia residente em outros países}

\begin{tabular}{|c|c|}
\hline País de residência & Paraguaios \\
\hline Argentina & 550.713 \\
\hline Espana & 135.517 \\
\hline Brasil & 40.000 \\
\hline EUA & 20.023 \\
\hline
\end{tabular}

Fonte: PNUD (2009).

As análises sociológicas da emigração paraguaia têm-se concentrado, majoritariamente, na Argentina, particularmente junto aos grandes centros urbanos, principalmente Buenos Aires. De modo geral, a inserção dos migrantes na Argentina tem sido caraterizada pelos trabalhos precários, geralmente vinculados à construção civil ou aos serviços domésticos ${ }^{10}$ - vários autores têm destacado $^{11}$ a divisão de gênero neste âmbito (homens na construção civil e mulheres no trabalho doméstico).

Em relação ao trabalho doméstico, as pesquisas apontam diferentes tendências. Pacecca ${ }^{12}$ se propõe a entender como as relações de gênero organizam as trajetórias laborais de migrantes, com enfoque nas redes de mulheres; enquanto outros autores ${ }^{13}$ se dedicam a pesquisar a organização dos vínculos de cuidado na esfera familiar durante a migração, apontando a ausência da redistribuição dos papéis das domésticas ou a discriminação da mulher no processo migratório.

\section{Referências Bibliográficas}

BRAGE, Eugenia. Redes sociales y trayectorias migratorias de mujeres paraguayas en la Ciudad de Buenos Aires. IV Taller Paraguay desde las Ciencias Sociales. Rosario, 2011. Disponível em: < http://paraguay.sociales.uba.ar/files/2011/08/P_ Brage_2011.pdf $>$. Acesso em: 12.01.2014.

BRUNO, Sebastián. Migrantes paraguayas y el servicio doméstico en Buenos Aires.

${ }^{10}$ CARBONETTI, Adrián; GOMEZ, Néstor; PERETTI, Gustavo. Características demográficas y ocupacionales de la población paraguaya residente en la provincia de Santa Fe (Argentina).

11 HALPERN, Gerardo. Etnicidad, inmigración y política. Representaciones y cultura política de exiliados paraguayos en Argentina; BRUNO, Sebastián. Migrantes paraguayas y el servicio doméstico en Buenos Aires. Diferencias y desigualdades; BRAGE, Eugenia. Redes sociales y trayectorias migratorias de mujeres paraguayas en la Ciudad de Buenos Aires.

12 PACECCA, María Inés. Género, situación familiar y trayectoria laboral en mujeres migrantes.

${ }^{13}$ SANCHIS, Norma; RODRIGUEZ ENRIQUEZ, Corina. Cadenas Globales de Cuidados. El papel de las migrantes paraguayas en la provisión de cuidados en Argentina; BRAGE, op. cit. 
Diferencias y desigualdades. Ponencia presentada en el 4to Congreso Paraguayo de Población, organizado por la Asociación Paraguaya de Estudios de Población. Asunción: Paraguay. 2011.

CARBONETTI, Adrián; GOMEZ, Néstor; PERETTI, Gustavo. Características demográficas y ocupacionales de la población paraguaya residente en la provincia de Santa Fe (Argentina). I Taller Paraguay como objeto de estudio de las ciencias sociales. Posadas: IGG. UNAM. 2009.

CEPAL - COMISION ECONOMICA PARA AMERICA LATINA Y EL CARIBE. América Latina y el Caribe: migración internacional, derechos humanos y desarrollo. PIZARRO, Jorge M. (ed.). Santiago: CEPAL, 2008.

CESPEDES, Roberto. Familias en Paraguay. Análisis sociohistórico de estructuras familiares y pobreza. In UNFPA y ADEPO. Familia y pobreza en el Paraguay. Resultado de las investigaciones. Asunción: UNFPA y ADEPO, 2004.

DIRECCIÓN GENERAL DE ESTADÍSTICA, ENCUESTAS Y CENSOS (DGEEC). Principales resultados de pobreza y distribución del ingreso. EPH 2009. 2010.

HALPERN, Gerardo. Etnicidad, inmigración y política. Representaciones y cultura política de exiliados paraguayos en Argentina. Buenos Aires: Prometeo, 2009.

- Historia de un hecho histórico: Referéndum constitucional y migración paraguaya, 2012. Disponível em: <www.razonypalabra.org.mx/N/ N79/V79/14_Halpern_V79.pdf >. Acesso em: 15.10.2014.

LEVITT, Peggy; GLICK-SCHILLER, Nina. Conceptualizar a simultaneidade. In MARQUES, Margarida. Estado-Nação e Migrações Internacionais. Lisboa: Livros Horizonte, 2010.

ODDONE, Hugo. Algunas consideraciones sobre los fundamentos ideológicos de la política migratoria paraguaya. Diponivel em: <http://www.alapop.org/2009/ index.php?option $=$ com_content\&view $=$ article $\& i d=621 \& \mathrm{ltemid}=339>$. Acesso em: 23.09.2014.

PACECCA, María Inés. Género, situación familiar y trayectoria laboral en mujeres migrantes. In Mujeres en escena. Santa Rosa: Universidad Nacional de La Pampa, 2000.

PALAU, Tomás. El Marco expulsivo de la migración paraguaya. Migración interna y migración externa. In HALPERN, Gerardo. Migrantes; perspectivas (criticas) em torno a los procesos migratórios del Paraguay. Asunción: Ápe Paraguay Migrantes, 2011.

PNUD - PROGRAMA DE LAS NACIONES UNIDAS PARA EL DESARROLLO PARAGUAY. Ampliando horizontes: Emigración internacional paraguaya. 2009. Disponível em: <http://www.unfpa.org.py/download/hdi_py_2009.pdf > . Acesso em: 15.02.2014.

SANCHIS, Norma; RODRIGUEZ ENRIQUEZ, Corina. Cadenas Globales de Cuidados. El papel de las migrantes paraguayas en la provisión de cuidados en Argentina. Buenos Aires: ONU Mujeres (MIMEO), 2011. 